\title{
GUERRA IRREGULAR
}

Irregular War

\author{
Cláudio Umpierre Carlan*
}

\begin{abstract}
VISACRO, Alessandro. Guerra irregular: terrorismo, guerrilha e movimentos de resistência ao longo da História. São Paulo: Contexto, 2009. ISBN 978-85-7244-433-0.
\end{abstract}

A vitória mais completa e feliz é aquela em que o inimigo é compelido a abandonar seus propósitos, sem nenhum dano a nossa parte.

Belisário, general bizantino (505-565)

A guerra irregular, tema relativamente novo no Brasil, vem sendo analisada e estudada desde meados da década de 1970. A derrota das forças armadas norte-americanas e a aplicação da teoria de guerra de Mao Tsé-Tsung (estratégia maoísta) pelo comandante vietnamita Vo Ngueyn Giap (hoje com quase 100 anos), deram uma nova visão ao universo da estratégia militar. Ambos ex-professores de História.

A "guerra total", defendida pelo general prussiano Carl von Clausewitz, no início do século XIX, cai para um segundo plano nos séculos XX e XXI. O próprio Clausewitz foi professor de Estratégia e Guerra Irregular na Escola Militar de Berlim, totalmente remodelada para a nova realidade militar que a Europa vivia no século XIX. A promoção por mérito, exames físicos e intelectuais para os oficiais (anteriormente era privilégio da nobreza) e a humanização do tratamento aos praças (sargentos, cabos e soldados) são conquistas desse período. Clausewitz, um estudioso de História, Literatura e Filosofia, rompeu com a cadeia hierárquica em defesa dos seus ideais.

O autor, Major Alessandro Visacro, é membro das Forças Especiais do Exército Brasileiro, e vem, há alguns anos, se dedicando a uma análise detalhada dos clássicos sobre estratégia militar. Estratégia essa que pode

* Unifal - Universidade Federal de Alfenas. 
ser muito útil no nosso dia a dia. Segundo Sun Tzu, em a Arte da guerra: "Se você conhece o inimigo e conhece a si mesmo, não precisa temer o resultado de cem batalhas. Se você se conhece, mas não conhece o inimigo, para cada vitória ganha sofrerá também uma derrota. Se você não conhece nem o inimigo nem a si mesmo, perderá todas as batalhas".

Por meio de uma identificação inicial, seguida de uma profunda análise crítica, Visacro nos apresenta o conceito e os agentes históricos responsáveis pela origem da Guerra Irregular. $\mathrm{O}$ autor realiza uma pequena introdução, "Da Antiguidade às torres gêmeas", página 15, passando com sucesso pelos tortuosos labirintos da História. É bem verdade que poderia ter se aprofundado mais sobre a Guerra na Antiguidade (existem pesquisas e publicações sobre o tema no Brasil, desenvolvidas pelo Núcleo de Estudos Estratégicos da Unicamp, coordenado pelo professor Pedro Paulo Abreu Funari). Afinal, o sistema de guerrilhas foi muito aplicado por egípcios, hititas, assírios, hebreus, espartanos, entre outros. As transformações militares no século IV da Era Cristã preocupavam o historiador militar Vegécio. Esse descrevia a entrada dos povos germânicos (vulgarmente conhecidos como bárbaros) nas legiões romanas, assumindo inclusive postos de comando. Desse modo, aos poucos, esses povos irão acrescentar uma nova identidade às tropas, o que o historiador Peter Brown, da Universidade de Princeton, defende como o surgimento das batalhas medievais. Porém, esse fato em nada diminui a originalidade e a importância da obra.

Na primeira parte do livro, são expostas a evolução do sentido da guerra na História. Uma breve introdução sobre a guerra no mundo antigo e medieval, a guerra irregular surgindo como uma alternativa "da luta dos fracos" contra os poderosos impérios. A conduta do embates militares no século XX, contando com o auxílio do Kominter soviético (1919-1943) e a preocupação com o terrorismo. O general inglês Richard Clutterbuck, em meados na década de 1970, estabelecendo a guerra irregular como a guerra do futuro, sempre contando com o apoio popular que, segundo o autor, é imprescindível para o êxito das forças irregulares (página 128).

O interessante dessa primeira parte é a explicação da chamada "Guerra de Quarta Geração" ou 4GW. Trata-se de uma série de artigos publicados na revista do Corpo de Fuzileiros Navais dos Estados Unidos (USMC), que divide a História da Guerra em fases (página 38): 
a) a primeira geração da guerra moderna seria compreendida entre o término da Guerra dos 30 anos (1618-1648) e as Guerras Napoleônicas. Guerras pré-revolução industrial, caracterizadas pelo combate linear, formações cerradas, semelhantes às grandes paradas militares muito bem representadas no filme $O$ Patriota, dirigido pelo cineasta alemão Roland Emmerich. Disciplina e obediência eram as ordens do dia. Algumas manobras realizadas pelo Corpo de Fuzileiros Navais brasileiro, como por exemplo o avanço sobre o fogo em movimento, ainda estão presas a esse padrão;

b) a segunda geração, já industrializada, da qual o autor destaca as batalhas genocidas da Guerra da Secessão ou Civil Norte-Americana (18511865) e a Guerra do Paraguai (1864-1870), culminando com a Primeira Guerra Mundial (1914-1918). O historiador inglês Eric Hobsbawm define como o longo século XIX e o curto século XX. Segundo Hobsbawn, o final do século XIX ocorre em 1918, com o fim Primeira Guerra e dos grandes impérios (austro-húngaro, turco-otomano e o II Reich alemão);

c) a terceira geração caracterizou-se por um retorno à tática e à mobilidade (blitzkrieg ou guerra relâmpago do III Reich alemão, com o nazismo), não linear, baseada na velocidade, deslocamento e surpresa (invasão dos nazistas na Polônia e o desembarque aliado na Normandia, em 1944);

d) na quarta geração, os oponentes não serão os Estados nacionais, mas, sim, grupos que combatem e morrem por uma ideologia.

O autor conclui, página 40, essa primeira parte com muita clareza, não ficando preso a uma ideologia ou a uma hierarquia ultrapassada: "Em termos gerais, podemos afirmar que, atualmente, a esmagadora maioria dos profissionais militares, graças à ortodoxia e ao ceticismo da sua formação, são soldados de, no máximo, segunda geração [...] muitos poucos exércitos predomina uma cultura de terceira geração[...]”.

Na segunda parte, são tratados temas sobre os principais conflitos e campanhas irregulares do século XX. Visacro destaca que nenhum dos grandes líderes guerrilheiros deste período eram militares de formação: Lawrence era arqueólogo, com forte influência clássica, Tsung e Giap eram professores, Collins, Tito e Castro políticos de oposição e líderes sindicais (principalmente Tito).

Nesses conflitos do século XX, podemos destacar a Revolta Árabe (retratada no filme Lawrence da Arábia, de David Lean). Além do apoio britânico (império turco-otomano, aliado do império alemão, dominava a 
região), o profundo conhecimento de Lawrence do idioma, costumes e da causa árabe foram fundamentais para o êxito da missão; os partisans na antiga Iugoslávia, comandados por Josip Broz Tito, contavam com uma larga experiência na Guerra Civil Espanhola, ao lado das Brigadas Internacionais; a resistência francesa, maquis, opositores ao governo colaboracionista de Vichy, entre outros. O grande equívoco da resistência francesa foi o "autoconhecimento". Todos eram amigos, se conheciam mutuamente. Bastou um grupo ser capturado, torturado pelos nazistas, para informar toda a operação. Jean Moulin (1899-1943), Diretor do Conselho Nacional de Resistência, apesar da forte tortura sofrida, jamais deu qualquer informação à Gestapo. Com esse fato, os alemães infringiram uma das regras básicas adotadas pelos romanos e defendida por Sun Tzu (Arte da guerra): aliança com os vencidos, tratando-os com decência e respeito à população civil.

Uma das ordens mais severas de Mao Tsé-Tsung, durante a Revolução Chinesa, era o respeito aos civis. Qualquer soldado ou oficial maoísta que roubasse ou humilhasse um civil era severamente punido. Muitas vezes com a pena de morte. Com isso, Mao contou com o apoio das diversas etnias chinesas e realizou uma reforma geral no exército. Os comandantes eram escolhidos nas próprias fileiras, tratavam os soldados com educação, conviviam nos mesmos alojamentos e refeitórios.

O autor descreve a estratégia das tropas norte-vietnamitas, comandadas por Giap, seguindo à risca o conceito maoísta de guerra, evitando, sempre que possível, o confronto aberto com o poderoso exército dos Estados Unidos. Giap e suas tropas possuíam uma larga experiência nas guerras de independência contra a França e a maneira ocidental de guiar as batalhas, consagrada durante a Segunda Guerra Mundial (1939-1945).

Outros pontos de destaque dessa segunda parte são uma análise sobre o IRA, na Irlanda; a luta da Argélia pela independência, contra a França; a Revolução Cubana e os conflitos árabe-israelenses.

$\mathrm{Na}$ terceira parte, Visacro estabelece uma definição e uma classificação da guerra irregular, como ambiente favorável (condições sociais favoráveis, uma simbologia que fortalece a crença ideológica), suas características, dentre outras. Destacamos nesse capítulo a relação da guerra irregular e o Direito Internacional Humanitário (Convenção de Genebra). O autor descreve a preocupação de Grotius, de Vettel e Hobbes, no século 
XVII, em estabelecer limites para os conflitos bélicos, protegendo a população civil. Von Rommel, marechal alemão, na campanha da África (início da década de 1940), utilizou esses conceitos para o tratamento dos prisioneiros de guerra. Infelizmente, o alto comando nazista não fez o mesmo na Europa, na última fase da Segunda Guerra. O autor cita vários artigos da Convenção de Genebra, referentes a populações civis e prisioneiros.

Na página 279, Alessandro Visacro conceitua, com sucesso, terrorismo e atos de terror. Cita alguns momentos históricos (Revolução Francesa, Rússia pré-revolucionária), a participação da sociedade secreta Mão Negra no assassinato do herdeiro do trono austríaco; Ira, sob o comando de Collins, nos anos 20, o surgimento do terrorismo religioso com a revolução islâmica, culminando com os atentados perpetrados pela Al-Qaeda em Nova York, Washington, Londres e Madri.

Um dos grandes méritos do livro consiste em apresentar uma análise detalhada e aprofundada de um tema atual e vivo entre nós, ao qual o Estado e a cúpula das Forças Armadas dão pouca importância. O autor cita a guerra oculta travada nas grandes metrópoles brasileiras, principalmente Rio de Janeiro e São Paulo. Na falta da "mão do Estado", o crime organizado, com armamento e treinamento adequado, controla a situação, transformando "morros" em "feudos" e os contraventores em "barões" ou "Robin Hoods" modernos.

O major Alessandro Visacro não subordina sua análise aos velhos padrões do século XIX ou da Segunda Grande Guerra, importantes na época, porém hoje obsoletos, sem sentidos e dispendiosos para o Estado (principalmente para o contribuinte). Porém, pelo contrário, o autor apresenta um quadro variado e original. Não uma apologia à guerra, mas uma maneira de conhecer esses conflitos, estudá-los, analisá-los, para então evitá-los.

Portanto, trata-se de uma leitura obrigatória para todos os membros das Forças Armadas, estudantes das Escolas Militares, policiais federais, civis e militares, alunos e professores de História, Filosofia e Ciências Sociais, área de humanas de uma maneira geral. Para aqueles que buscam interpretações e informações sobre um tema polêmico, que coloca em risco o Estado Nacional como conhecemos. 


\section{Referências}

BASSFORD, Christopher. Clausewitz in English. The reception of Clausewitz in Britain and America 1815-1945. New York/Oxford: Oxford University Press, 1994.

BROWN, P. O fim do mundo clássico. De Marco Aurélio a Maomé. Trad. Antônio Gonçalves Mattoso. Lisboa: Editorial Verbo, 1972.

HOBSBAWN, Eric. Era dos extremos. O breve século XX. Trad. Marcos Santarrita. São Paulo: Companhia das Letras, 1996.

LIDDELL HART, Basil H. As grandes guerras da história. Trad. Aydano Arruda. Revisão técnica e anotações: Gal. Reynaldo Melo de Almeida. 3. ed. São Paulo: IBRASA, 1982.

SUN TZU. A arte da guerra. Adaptação e prefácio de James Clavell. Trad. José Sanz. 17. ed. Rio de Janeiro: Record, 1996.

VEGÉCIO. A arte militar. Introdução de Paulo Matos Peixoto. Trad. brasileira de Gilson César Cardoso de Souza. 1. ed. São Paulo: Editora PAUMAPE S.A., 1995.

Recebido em julho de 2010. Aprovado em setembro de 2010. 